\title{
A Educação Médica diante das Necessidades Sociais em Saúde
}

\author{
Medical Education and its Relationship to \\ Social Needs in Health
}

Rogério Amorelti

PALAVRASCHAVI:

- Educaçāo Médica

- Intcrnato e Resictência;

- Recursos Hunauses em Siujde: Tendencias;

$-\operatorname{SLS}(\mathrm{BR})$

- Deterninação das Nec:essidades dos Serviços de Sauide.

KEYYWORISS

- Educatien. Medical:

- Internship and Residency.

- Health M:Inpuwer-Trends;

$-S U S(B R)$ :

- Needs Assessment.

Recebido com: 25/02/2005

Aprovatua cm: 16/06/2005

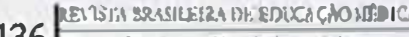

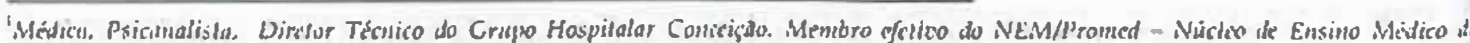

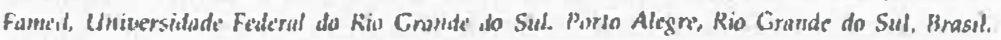




\section{INTRODUÇĀO}

A complexidade da formação de recursus humanos para a saúde é grande, sendo preciso situar minimamente o contexto sócio-histórico c cvolutivo em que ela ocorre.

Desde a segunda metade do sćculo 20, a área da saúde foi palco de transformaçāo com impacto mundial de grandes proporçōes, pelas mudanças científico-tecnológicas $\mathrm{cm}$ relação às غ́pocas anteriores e pelas contradiçōes ideotógicas, filosóficas céticas dai decorrentes.

O desenvolvimento cientifico aplicado, sustentado pelas tecnologias de informática c automação, aumentou a cficácia dos procedimentos diagnósticos e terapêticos. A produção) de medicamentos, de instrumentos de alta precisão, de técnicas cirúrgicasavançadas, propiciada pelos equipament(os e uso dessas drogas, tornou a medicina resolutiva para um grande número de doenças agudas, crönicas, traumaiticas, congênitas ou hereditárias, nas quais, anteriormente, poucos resultados positivos se poderiam obter. Transplante de órgãos, uso de próteses artificiais e orgânicas, angioplastia, ecografia, tomografia computadorizada, ressonância eletromagnética, equipamentos a laser, genética molecular, tera pias gênicas c toda sorte de equipamentos eletrônicos e medicamentos farmacológicos são a expressão da parte mais visivel desses avanços'.

Esta revolução nas cièncias biomeidicas impulsionou um mercado mundial altamente especializado, restrito c agressivo, capaz de girar e concentrar um grande volume de dinheiro c promover lucros significativos. A saúde transformou-se rapidamente numa banca globalizada de negócios multinacionais, com um disputado movimento de inclusão, nele, de especialistas de diferentes categorias. Este potente fator estrutural promoveu um processo sem precedentes de cooptação passiva ou ativa de profissionais, não exclusivamente da área médica, que passaram a ser parcciros essenciais das emergentes ind ústrias farmacêuticas, de equipamentos, materiais e insumos. Esta efica\% parceria nāo foi, contudo, isenta de desvios e seqüclas. A incorporação tecnológica desenfreada passou a determinar tanto a organização e gestāo dos hospitais, clínicas, faculdades e consultórios, como a formação dos profissionais. O foco das práticas médico-hospitalares concentrou-se progressivamente na realização dos procedimentos propiciados através de instrumentos de diagnóstico e tratamento e no uso de drogas. A lógica da produtividade tomou conta da relação profissional-paciente.

Na área médica, a mais afctada neste processo, a renovacào tecnológica em velocidade sem precedentes passou a determinar a necessidade de atualizaçāo permanente nos conteúdos do aprendizado c na formação dos profissionais. Fundamentos c conceitos anteriores de uma medicina bascada na relação médico-paciente, na escuta dos problemas, no humanismo è na consideração da unidade indissolúvel do corpo e mente foram muitas veres deixados de lado. A pessoa e suas necessidades, as populaçōes c suas necessidades, atendidas em domicílio pelo médico da família, até então tidas como objetos importantes da medicina e da sacide puiblica, foram sendo relegadas, com o argumento da cficácia dos resultados obtidos, fossem eles em termos de diagnóstico ou de terapêutica clínica ou cirıirgica.

A pesquisa biomédica afirmou progressivamente os bons resultados da nova clínica. As práticas baseadas nas cvidências demonstradas por procedimentos, medicamentos e técnicas produziram a emergência permanente de novos produtos e innvaçñes. O ensino se concentrou decisivamente nos hospitais, constituindo o morlerıno modelo hospitalocêntrico de assistência médica e o principal campo da formação. Pesquisa, inovaçōes, ensino c assistência se reforçaram constantementec deram um direcionamento irresistivel às aplicações do conhecimento cientifico neste periodo.

Segundo Boaventura de Sousa Santos²,

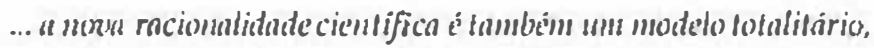
nn medida t'm que nega o tarifler racional a lodtus as formas de

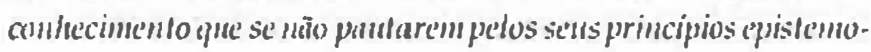

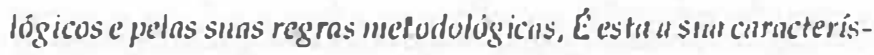
lica fundumenulal e a gue medhor simboliza a ruplura do nevo paradigma cienlifico com os gene o precedem. Esti comsubstanciadis, com crescenfe definiçĩo, nn fcorin heliocênl rica do motimento dos planelas de Copérnico, mas leis de Kepler solure as órbitas dos Hhmetns, nas leis de Colilen sobre a gueda dos corpos, na grande sinlese da oriem cósmica de iveruton ce, findmente, no consciêncin filusiffica nuc the confere'm Bacon e', solureluto, De'scarte's.

Este pano de fundo marcou profundamente o ensino dos médicos e demais especialistas da área da saúde a partir dos anos $70 . \mathrm{O}$ diversificido desenvolvimento tecnológico impulsionou a divisão do (raballno especializado, influenciando de maneira sistemática os conteudos curriculares, com a departamentalizaçĩo curricular.

Na medicina, a necessidacle de trcinamento c capacitação) dos profissionais para o uso das tecnologias consagrou as residéncias mėdicas e a lógica da formação em serviço com aumento da formação de especialistas, nos hospitais de ensino. A gestão político-administrativa das instituiçōes de satide, públicas" ou privadas, urientou-se, no geral, nesta direção.

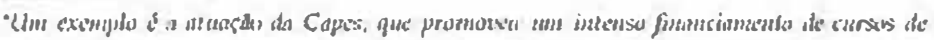

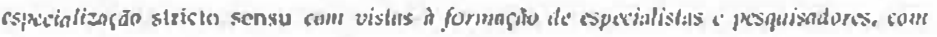

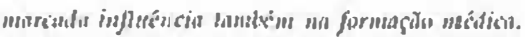


Todo este desenvolvimento das ciências e tecnologias biomédicas trouxe resultados espetaculares, mas não houve acesso eqüitativo a elas.

Contudo, neste mesmo periodo, também foram buscadas novas soluçōes que fucalizaram as possibilidades da saúde pública e de outras referências para as práticas integrais em saúde. Entre elas, destacou-se a Conferência Internacional de Alma-Ata³, ocorrida no Cazaquistāo (1978), que promulgou a diretriz "saúde para todos", juntamente com a proposiçāo da atençāo primária em sauide (APS), como cstratégia para atingir tal objetivo mundialmente até o ano 2000. Embora estes propósitos não tenham sido alcançados no prazo previsto, a especialidade do médico generalista, médico de família c comunidade passou a ser vista como complemento indispensável ao modelo das especialidades, consolidando a idéia de estabelecer uma ampla base de clínica geral, familiar e comunitária para a sustentação dos sistemas de saúde. O conceito das abordagens e práticas multiprofissionais e interdisciplinares foi também reconhecido como o único caminho para a integralidade da assistência co adequado cuidado às pessoas $\mathrm{em}$ suas múltiplas necessidades. Inúmeros movimentos $\mathrm{c}$ instituiçōes passaram a atuar direcionados a estes objetivos."

No campo ético, uma reação acs paraefeitos da inusitada incorporação tecnológica biomédica foi o aparecimento da bioética, como um novo paradigma de reflexão e discussão dos limites éticos e juridicos da manipulação do corpo, das distorçōes decorrentes do primado da tecnologia ou mesmo do acesso restrito aos benefícios do uso da moderna tecnociênciaง. Também significou dizer que a situação do homem de todos os homens e mulheres - passou a ser un problema ético para o homem, ou seja, uma macroética ${ }^{5}$ se tornou necessária, fundada no principio da responsabilidade com as populaçōes, o meio ambiente e as geraçōes futuras ${ }^{6}$

Cautcla c prevenção se fizcram necessárias nāo só diante dos perigos da aniquilação nuclear, dos danos à ecosfera ou à biosfera, das guerras genocidas, mas também frente à brutal exclusảo social, que promove, no periodo de maior desenvolvimento das forças produtivas e das condiçōes tecnocientificas, um incremento perverso da pobreza, da miséria c da fome para grandes contingentes da população mundial.

Os graves problemas que se acumularam na área médica en decorrência desta evolução, con repercussỏes mundiais, levaram autores médicos a relletir criticamente e a buscar soluçỏes para corrigir estes rumos?.

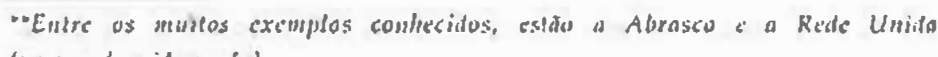
(woweresthrunsita.urg. br).
Propostas de polílicas de acesso equiitativo aos recursos disponiveis e de organização racional dos sistemas de saúdc começaram a ser construidas, em menor ou maior grau, em muitos países.

Este processio histórico de alta incorporaçñ tecnológica aconteceu também no Brasil\$, a partir da década de 1970. Aqui, porém, o movimento sanitarista que se opôs radicalmente à ditadura militar, após o golpe militar de 1964, conseguiu influenciar, durante o processo de abertura democrática, a inclusão do capítulo referente à saúde da nova Constituiçāo de 1988 e a criação do Sistema Único de Saúde como lei constitucional.

O SUS e seu novo modelo assistencial foram um acontecimento raro c precioso. Tornou-se um dos maiores sistemas públicos de saúde do mundo, organizado $\mathrm{em}$ rede de serviços e garantindo acesso universal e gratuito a todas as pessoas, constituindo um fator de democratização e distribuição equiiitativa dos recursos aplicados. Traduziu-se, assim, em exemplo da participação do Estado na garantia dos direitos humanos e na realização de cidadania e jusliça social.

Segundo dados do Ministério da Saúde", atualmente cerca de $90 \%$ da população brasileira é usuária do SUS e somente $8,7 \%$ nāo o utilizam. Uma parcela de $28,6 \%$ dcs brasileiros tem como único recurso de assistència o SUS, c cerca de $61,5 \%$ utilizam os serviços assistenciais do sistema único complementado com algum plano de saúde ou atendimento particular, o que demonstra sua magnitude e importância.

Na alta complexidade, onde ocorrem os maiores gastos, 94\% dos transplantes de órgãos, por exemplo, sīo realizados e financiados atualmente pelo SUS. O Brasil tem o maior programa inundial de transplantes de orgāos, proporcionalmente à população.

Pode-se dizer que a organização dos serviços de assistência e cuidados em saúde conta, especialmente nos principais hospitais universitários de ensino e pesquisa do nosso país, com as tecnologias mais complexas disponiveis nos paises avançados. Entretanto, em muitas regiōes rurais e mesmo nas áreas urbanas, ainda persistem estruturas de saúde arcaicas, incficientes e incficazes, sendo que em muitos municipios sequer existe médico.

Estas são algumas das principais variàveis na discussāo da formaçāo dos recursos luumanos necessários à saúde no Brasil, sendo imperioso harmonizar a medicina efica com o uso racional das tecnologias disponiveis, em un sistema bem organizado. E também qualificar os profissionais de todas as categorias da saúde para uma assistência integral, humanizada c com responsabilidade pela continuidade cos cuidados prestados. 
Sintetizando, é preciso aproximar lógicas antagónicas de interesses conflitantes presentes no processo de incorporaçāo das tecnologias de ponta c nos corporativismos profissionais, em busca de integralidade dos cuidados de atenção à saúde das pessoas e da construção de um sistema racionalmente organizado, com dire trizes definid as, acesso eqüitativo c controle social. Para isso, ć central a incidência de políticas públicas de tistado, reguladoras desta transição.

\section{AS DISTORÇŌES NO ENSINO, NO SERVIÇO E NO SUS}

Conhecimentos diferenciados $\mathrm{c}$ nichos de poder promoveram a autonomia corporativa $e$ influenciaram tanto a assistência quanto o cnsino e a pesquisa. Serviços de saúde, entre cles os hospitais, buscaram a alta tecnologia. Livres iniciativas e não as necessidades reais de saúde da população prevaleccram nesse processo.

As garantias do consumo de equipamentos, materiais e medicamentos coincidiram com o favorecimento do mercado das empresas fabricantes, em harmonia com o reconhecimento do papel central dos profissionais cnvolvidos na execução dos procedimentos. O modelo hospitalocêntrico da saúde afirmou com uma nova lógica o poder institucional dos médicos, fortemente ancorado no conhecimento especializado. () procedimento técnico ganhou centralidade nas práticas médicas. Possibilidades de reconheci mento e afirmação social e econômica produziram uma indução irresistivel ao desenvolvimento das múl tiplas especialidades. O mercado do trabalho médico cresceu nesta dirç̧ão, para onde as empresas farmacêuticas c dc equipamentos bioméclicos e depois os sistemas público e privado da saúde dirigiram elevados investimentos financeiros.

O ensino, principalmente da medicina, organizou-se entảo quase totalmente scgundo esta lógica, fragmentando-se em disciplinas por especialidades. Grande acúmulo de conhecimentocientifico aco mpanhou o aparecimento das novas tecnologias. $\wedge$ pesquisa científica orientada pela lógica da cvidência c da cficácia dos procedimentos impulsionou o desenvolvimento de renovadas tecnulogias a medicamentos. $\Lambda$ própria ciência foi assim "apropriada" pela indústria c o comércio, assumindo o papel quase incvitável de avalizar a eficácia das novas tecnologias e medicamentos, que logo são disponibilizados neste mercado mundial que mobiliza e concentra, a cada ano, bilhōes $\mathrm{c}$ bilhōes de dólares.

Nos hospitais, a organização c a expansão dos scrviços também foram harmónicas com as necessidades de diagnósticos e tratamentos possibilitados pelos recursos disponivcis. Todo profissional, de nivel superior ou médio, que nảo estivesse diretamente vinculado à utilizaçăo da "tecnologia de ponta" perdeu visibilidade e teve seu prestígio institucional restrito. "Modernização do parque tecnológico" tornou-se quase sinónimo de qualidade e resolutividade, almejadas a qualquer preço.

A busca de expansão dos serviços hospitalares, segundo esta lógica, orientou o crescimento de vagas nas diferentes residências médicas das especialidades. $\Lambda$ produtividade focada nos procedimentos tornou indispensável ampliar os serviços, com o conscqüente aumento dos recursos humanos, materiais c financeiros disponiveis. A residência médica, de formação em serviço, passou a representar mão-de-obra especializada incorporada ao serviço, tornando-se vital à continuidade da boa assistência hospitalar.

$\Lambda$ expansảo da formação $\mathrm{cm}$ serviço, representada pela residência médica, passou a ocorrer então pela necessidade de organização dos próprios serviços médicos para as práticas hospitalares em cada contexto especifico, e não pelas nécessidades sociais de incremento da formação de profissionais de determinada especialidade. Contudo, esta mão-deobra especializada adicional ć temporária c precisa ser regularmente renovada, para que o beneficio de sua presença seja permanentc. "“. Estes serviços especializados funcionam adequadamente segundo a sua própria lógica, mas, simultaneamente, lançam no mercado de trabalho, todos os anos, um número crescente de especialistas. A definição das vagas nos programas das residências médicas ocorre, na maior partc das vezes, de forma autônoma e quase automática, segundo as próprias necessidades ou o desejo da especialidade.

$\Lambda$ presença de múltiplos especialistas trabalhando como generalistas em unidades básicas do sistema público, $\mathrm{cm}$ cquipes do Programa de Saúde da Família (I'S(i) ou fazendo plantóes em clínicas de pronto atendimento, prejudica o processo da assistência, pois cles nảo foram preparados para este tipo de trabalho.

Assim, un círculo vicioso se estabclcceu, capaz de promover uma progressiva e nefasta distorçăo, qualitativa c quantitativa, na formaçāo dos recursos humanos, diante das necessidades do SUS e das demandas prevalentes de saúde da populaçiou.

As especialidades médicas passaram a organizar tanto os departamentos e disciplinas das faculdades quanto os serviços médicos nos hospitais de ensino e nas clínicas. Daí decorre, a cada ano, a entrada "no mercado" de un elevado núme-

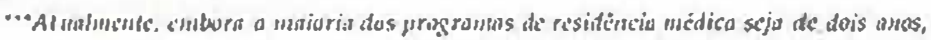

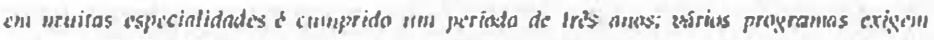

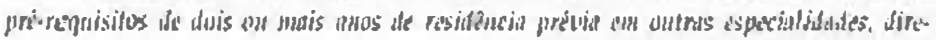

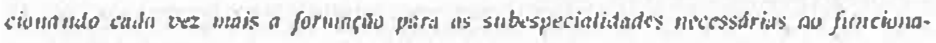

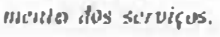


ro de especialistas capazes de diagnosticar ou tratar doenças muito específicas. Contudo, esses médicos com orientação focada desde os bancos universitários nāo sīo totalmente absorvidos no mercado existente, já que os locais prioritários de suas práticas, os hospitais puiblicos, filantrópicos ou privadose as clínicas especializadas, equipad as com tecnologias de ponta, possuem vagas de trabalho especializado limitadas e são restritos, geograficamente, aus centros urbanos maiores.

Neste contexto de formação miciça de especialistas e subespeciali stas, pelas dificuldades e elevados custos de interiorizaçāo da medicina, nas cidades do interior ucorre escasse\% de profissionais, pois lá cles não tériam as melhores condiçōes de exercício de suas práticas; já nas met rópoles, contingentes deles quedam-se frustrados, pela ausência de postos de trabalho condizentes com a sua formação.

No outro extremo, por motivos variados, algumas especialidades médicas sāo carentes, e o numero de profissionais disponiveis nāo atende às necessidades do sistema.

A municipalização da atenção básica à saúde transformouse $\mathrm{em}$ realidade, abrindo progressivamente um grande mercado de empregos aos médicos e demais profissionais da saúde no sistema público. O l’rograma de Saúde da l'amilia (PSI:), introduzido há alguns anos pelo governo brasileiro, é constituido por equipes multiprofissionais“" distribuidas na área geográfica de cada município, possibilitando uma cobertura ativa à saúde da população adscrita à área e coincidindo com os principios c diretrizes formulados desde a Conferência internacional de Alma-Ata. l’ara o seu sucesso, contudo, são necessários médicos com caracteristicas particulares: generalistas, aptos a diagnosticar e tratar a maioria das doenças prevalentes en cada regiào, e médiços de familia c comunidadc, capazes de se inserir num bairro, lidar com indicadores epidemiológicos e gualitativos próprios da assistência às pessoas, com cobertura populacional, e promover as práticas de vigilancia em saúde. Mas faltam ainda profissionais desta especialidade aptos para este trabalho especifico ${ }^{\cdots}$.

Hoje, muitos médicos de diferentes especialidades - geneticistas, cirurgiōes cardiacos, cirurgiōes gerais, urologistas, patologistas e outros - buscam trabalho em equipes do PSI;

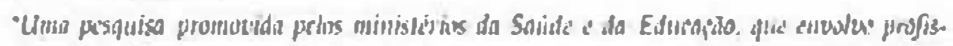

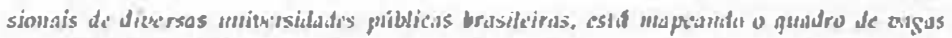

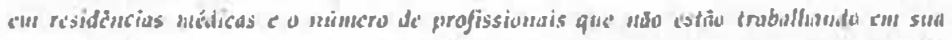

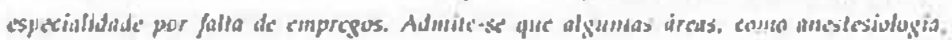

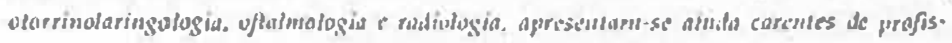
sirnsitis.

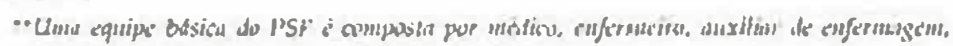

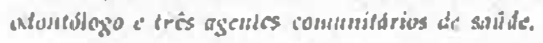

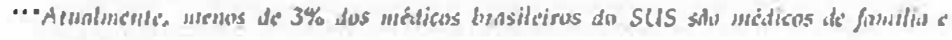
itomumidade. teıdo que desenwolver atividades para as quais nāo foram devidamente preparados. Indo contra a lógica do sistema, isto provoca outra distorção, representada pela redução da resolutividade e incficácia das práticas, com a intensificação dos encaminhamentos desnecessários e inadequados a outros profissionais de especialidades. Um grande ônus para us ustários e o aumento da fanma de ineficácia do SUS decorrem desta situação, além de um elevado turı-oier de profissionais. Além disso, é igualmente incorperrado ao SUS um percentual nāo desprezivel de médicos que não tiveram a formação completada através da residência médica “.”, o que também contribui para prejudicar o funcionamento do sistema, já que a formação curricular não oferece ao médico recém-formado as condiçōes para exercer adequadamente a medicina.

\section{O P'ERFIL DO PROFISSIONAL QUE FORMAMOS}

O perfil predominante do profissional médico da segunda metade do século 20, induzido pelas necessidades de uso das tecnologias, apresenta um conjunto de características gerais:

- Lssencialmente positivista, com enfoque biologicista c utilitário, já que estas são as características desenvolvidas tanto pelo referencial técnico-científico das instituiçoes formadoras quanto pelas exigéncias de busca de produtividade e competitividade constituidas no próprio mercado de trabalho;

- Com alto grau de competência profissional, pois sem este atributo um profission al que lida com alta tecnologia não tem possibilidades de se atirmar;

- Fortemente centrado $\mathrm{cm}$ sua especialidade, à qual sc dedica quase na integra;

- Predisposto à utilização de novas tecnologias, equipamentos e técnicas, devido à formação tecnicista;

- Com tendência a medicalizar o processo saúde-doença e a incorporar equipamentos c insumos;

- Alualizado, assiduo nos estudos e na formação cm serviço, já que precisa renovar constantemente seus conhecimentos, sob pena de ficar defasado e superado;

- Marcadamente individualista, pois toda a sua formação colabora neste sentido;

- Formado num modelo idealizado, coerente com príti. cas profissionais liberais e privativistas, construindo uma mentalidade eli tista da saude e estimulado a reali-

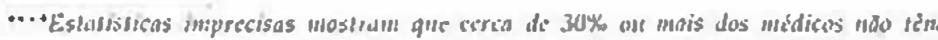

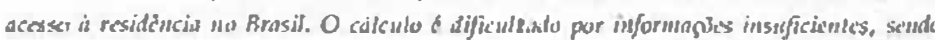

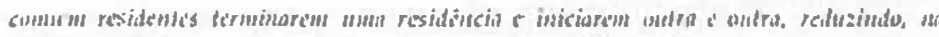

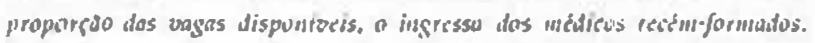


zaçāo de procedimentos motivados por interesses econômicoss;

- Resistente a trabalhar em igualdade de condiçōes com as outras profissīes da área da saúde, o que se acentua pelo fato de que a medicina se particularizou no uso da tecnologia, afirmando-se, assim, uma lógica de poder pelo saber;

- Paternalista na relação com o paciente c seus familiares, sendo este um dos aspectos que historicamente marcou a relaçāo médico-paciente;

- Onipotente na crença da cura das doenças, tendo este aspecto se intensificado com o aumento da eficácia dos procedimentos médicos;

- Altamente corporativista na defesa da manutençāo das situaçōes estabelecidas em torno do poder e do controle do saber constituido;

- Crítico do SUS e defensor de uma visão liberal e autónoma da profissāo, condiçāo que hoje, paradoxalmentc, quase inexiste em nosso país, fato que decorre da influência da cultura dos docentes, pesquisadores c preceptores médicos, sejam acadêmicos ou dos hospitais de ensino.

Como elementos negativos ou faltantes dessa formaçāo, podemos relacionar:

- Pouco conhecimento e nenhum compromisso com a organização do Sistema Único de Saúde, sendo este um fator político e ideológico que tem acompanhado a cducaçāo médica, afastando-a também dos estudos de sa úde coletiva, prevenção e promoção de saúde:

- Pouco envolvimento com aspectos administrativos $c$ gerenciais da gestāo da saúde pública;

- Pouca compreensão da importância do trabalho cm equipe multiprofissional, com integração de conhecimentos interdisciplinares, para uma assistência focada na pessoa e em suas necessidades;

- Fraca formação humanistica, psicológica, sociológica e filosófica necessária a um profissional médico;

- Despreparado para o atendimento das patologias prevalentes segundo a epidemiologia das diferentes regiōes do país;

- Pouco preparado psicologicamente para o exercício de sua profissāo;

- Nāo comprometido com aspectos políticos e sociais que propiciem a busca de soluçóes para us problemas de saúde da populaçāo;
- Com fraco conhecimento da realidade situacional, do ambiente e das condiçōes de vida das familias nas comunidades;

- Resistente a mudanças e, geralmente, defensur da manutençào do stafus quo vigente na sauide.

Em contrapartida, todos estes fatores somados contabilizam custos profissionais, sociais e mórbidos decorrentes de sacrifícios inerentes à formaçāo médica càs suas práticas profissionais, que pesam sobre a categoria com um ònus de elevado tributo vital, afetando a saúde principalmente dos mais jovens, o que quase nunca é reconhecido".

Vale destacar que estas características criticálveis nāo são exclusivas da formaçāo do médico. Elas também estāo presentes na educaçāo das demais profissīes da área da saúde. que, geralmente, apresentam ainda maior fragilidade na formaçāo de seus profissionais, que, em sua maioria, nāo chegam a atingir a qualidade existente nos aspectos tecnicista e cientificista da medicina.

Estes aspectos são gerais c não há um julgamento de valor implicito. Entretanto, és evidente que levaram, progressivamente, a categoria médica a um confronto com as outras categorias profissionais - é o caso da discussão atual da lei do ato médico - c também com a populaçāo, composta por usuários do SUS e dos demais planos de saúde, já que pacientes de clínica privada, hoje, praticamente inexistem.

A perda de prestigio social do médico é constante, c, neste isolamento corporativista, cle passou a ser () alvo quase exclusivo de açōes de responsabilizaçāo por erro, promuvidas por pacientes ou scus familiares. Dai, a relaçāo médico-paciente é agora potencialmente intermediada pela figura do advogado. Numa situaçāo laboral onde predomina a condiçāo de empregado ou prestador de serviços terceirizado de planos de saúde, com a queda de salários, a necessidade de gastos preventivos com seguros, reservas monetárias para pagar responsabilizaçōes judiciais ou, mais freqüentemente, prejuizos diretos em indenizaçōes de processos judiciais, torma-se cada vez. mais dificil e pouco atrativa a profissāo, tida pela população, até há alguns anos, como um verdadeiro sacerdócio, de alto valor social.

Fortemente marcados pela lógica do mercado, a assistēncia, o ensino e a pesquisa se desenvolvem sem sintonia com as expectativas da população e mui tas vezes em franco conflito com elas. Rediscutir e reverter este quadro é uma prioridade, que afeta a categoria médica, as demais profissỉes da saúde c a populaçāo. Trata-se de tarefa coletiva de govermantes, gestores, entidades representativas, instituiçōes de ensino, pesquisa e assistência, profissionais das diferentes profissiès da 
saúde, docentes, alunos c usuários que constituem a população do nosso pais - a principal beneficiária do processo de adequação da formação dos recursus humanos para a saúde e da construção do SUS quue queremos.

\section{QUE PROFISSIONAL P'RECISAMOS FORMAR?}

O mundo da medicina e da saúde está cm crise. O excesso de tecnologias que se renovam continuamente se contrapòe à completa caréncia de acesso aos mais elementares recursos da medicina e da saúde pública para grande parte da população. Para muitos, o médico é um vilào egoista c insensivel, representante dos interesses das industrias farmacêuticas e biotecnulúgicas.

Neste contexto, nossa época apresenta novas exigências aos profissiunais da saúde én geral c ao médico em particular. A profissào médica está vivendo uma profunda perda de identidade. $A$ identidade do médico se constituiu historicamente com caracteristicas muito particulares e enfrenta agora um grande conflito: sobreviver sem mudanças ou mudar evoluindo conforme as expectativas da sociedade atual, que tensionam os posicionamentos político-sociais, a formação acadêmica e as práticas médicas. A educaçāo profissional carece de uma reflexividade critica que possibilite a adequaçāo do médico às expectativas sociais"l. Por isso, é necessário considerar as circ uustàncias histórico-soxiais do processo que levou ao atual modelo da formação dos médicos e dos sistemas de sa uide constituídos. Assim, o perfil dos novos profissionais está se delineando por exigências da sociedade. Fm contrapartida, é preciso o reconhecimento do trabalho do médico e dos demais profissionais da área da saúde, com a retribuição por meio de salários adequados c a valorizaçào das profissões c carreiras.

Entre os atributos da vocação desse novo profissional médico, podemos incluir:

- Desenvolvimento de uma visão reflexiva e critica a respeito de sua profissão e de suas práticas;

- Ampliação de conhecimentus humanisticos em ciências sociais, antropologia c filosofia, capazes de propiciar esta reflexividade crítica;

- Manutenção e renuvação permanente dos conhecimentos cientifico-tecnológicos propiciados pela moderma tecnociência, que de forma alguma podem ser abandonados, mas precisam ser incorporados c utilizados com senso crítico e racionalidade;

- Aumento dos conbrecimentos baseados na epidemiologia, para a assistência resulutiva das patologias prevalentes nas populaçōes;

- Maior participação colctiva na gestào do sistema público de saúde;
- Conhecimentos de comunidade, família e técnicas grupais;

- Ampliação dos conhecimentos e das práticas multidisciplinares e interdisciplinares necessárias ao trabalho em equipe multiprofissional e integraçāo com os profissionais das demais profissōes da área da saúde;

- Aumento dos conhecimentos em psicologia, saúde mental c construção de subjetividade, que são recursus de relacionamento fundamentais às práticas dos profissionais da saúde;

- Ampliaçāo dos conhecimentos em satide coletiva, gestão da saúde e informação em saúde, segundo as diretrizes do SUS;

- Incorporação dos conhecimentos de educação para a promoçào da saúde, de métodos de ensino-aprendizado e de tecnicas pedagúgicas de preceptoria, tutoria e outras;

- Incorporação dos conhecimentos sobre cuidados e responsabilização das equipes de saúde às pessoas assistidas, com continuidade da assistência em toda a linha de atençāo à sua saúde, desde o cenário pré-hospitalar, no hospitalar c tambén no pós-hospitalar;

- Integração dos conhecimentos e práticas da assistência, do ensino e da pesquisa, com prioridade para as açỏes de atenção às necessidades concretas de saúde da populaçào;

- Inclusão da bioética como paradigma de orientação ética ${ }^{12}$ pelos direitos humanos das pessoas, das populações e das gerações futuras, nas práticas cotidianas $e$ atenção para todos os fatores éticos necessários às mudanças un cultura médica'3.

Todas as iniciativas referentes às mudanças na educaçāo médica devem convergir para o propósito da formação destes novos profissionais, em busca de suas novas caracteristicas. Evidentemente, um grande entrave neste processo é a própria formaçāo dos docentes médicos, tutores e preceptores, modelos para seus alunos e residentes, pois eles estão marcados justamente pelos atributos que dào o caráter formativo aos alunos das faculdades de medicina e aos profissionais recém-egressos das residências. Portanto, uma das questões fundamentais a considerar é como educar os educado. res, para que correspondam às necessidades c demandas sociais da área da saúde, trazendo para o debate o saber/fazer docente e o saber/fazer profissional't. E interrogar-se sobre como transformar a preocupaçāo com o outro - nossos pacientes, pessoas que vivem em nossas comunidades, pertencentes como nós a uma população específica, deste pais da América Latina - em meta de nossos cuidados. 
Lista ć a nossa dificil, mas nāo impossivel tarefa. Cabc aos ministérios da Educação e da Saúde-principais protagonistas públicos deste processo de mudanças - articular suas pulíticas de governo com vistas à indução dos centros formadores em direçāo a objetivos comuns pactuados.

\section{COMO FORMAR O NOVO PROFISSIONAL MÉDICO?}

$\Lambda$ formação do nov'(o médico cstá condicionada à mudast ça na educação também dos demais profissionais da área da sauide, de niveis superior e técnico. Este processo deve ser simultáne(o, inteğrado, progressivo e solidário. (O foco no médies significa que é em torno delé que se estrutura grande parte da distorçōo da educação atual e que a mudança n. formação dos profissionais da medicina é central, embora não) exclusiva e nem suficiente para o exito deste processo.

É preciso que a educaçĩo médica se estabcleça definitivamente em novos cenários, lá onde as práticas assistenciais estcjam ocorrendo e nāo sumente no hospital. A integração entre ensino, pesquisa e serviço deve ser ampliada, abrangendo as unidades sanitárias, os postos de sacide, os prontcatendimentos, as emergèncias, os programas de assistència domiciliar, os centros de atenção) psicoss()cial, as escolas c outros locais. Os alunos e os residentes precisam compor com os profissionais de todas as catcgorias que trabalham na sacide, compreender as dificuldades e as possibilidades das práticas conjugadas em saude c viver o cotidiano do SUS ${ }^{15}$.

Os programas de residéncias multiprofissionais em saide, integradas com as residéncias médicas, são tambím um forte estimulo indutor de mudanças positivas para a qualificaçāo do modelo de assistência.

São muitos us espaços coletivos, formais e informais que buscam reorientar a formaçào médica no Brasil, inclusive as politicas publicas do governo federal.

Cabe destacar primeiramente o Promed - Programa de Incentivo a Mudanças Curriculares nus Cursos de Medicina- uma açāo interministerial (MS/MFC) de apoio às escolns médicas para a adequação do ensino c a produção do conhecimento e dos serviços no pais, na lógica da reafirmação dás orientaçòes contidas nas Diretrizes Curriculares dos Cursus Médicos e na qual estāo incluidas 20 universidades brasileirns de diferentes regioúcs, que tiveram seus projetos de mudanças sclecionadoss para participar.

Importantes movimentos já institucionalizados cm diversảs instâncias formais, reunindo também as entidades médicas, buscam avaliar a qualidade do ensino médico e, por intermédio da Cinacm; já recomendam, como um dos principios de descnvolvimento da docência nas escolas médicas, a atua- ção prática em serviços e/ou comunidade desde o inicio do curso, em todas as atividades docentes, com integração ensino-serviços'l6.

Alguns instrumentos tegais são referèncias decisivas para as mudanças discutidas, entre cles: a Constituição licderal (1988); a Leji Orgânica do SUS (no 8.080, de 1990); a Lci das Dirctrizes e Bases da liducaçāo Nacional (n 9.394 de 1996); o parcer sobre as Dirctrizes Curriculares Nacionais dos Cursos de Ciraduaçāo em linfermagem, Medicina e Nutrição) (no 1.133/1997), do Conselhos Nacional de Educação; a Declaração) Mundial sobre Educação Superior no Século 21: Visĩo e Ação, da Unesco (1998); o Plano Nacional de Graduação do liorgrad (1999); us Relatórios das Cunfurèncias Nacionais de. Saude, particularmente o da 11` Conferència (2000); a Resolução nu 4 do CNE:, que institui as Diretrizes Curriculares Naci()nais do Cursos) de Graduaçĩo en Medicina (2001); a Portaria Interministerial ne 610 do MFC e a MS (2002), que institui o Promed * .

As portarias interministeriais de no $1.000,1.005,1.006 \mathrm{e}$ 1.007 (2004), que estabelecen critérios de certificação dos hospitais de cusino, prevendo a contratualizaçāo do financiamento através de Contratos de Metas, pactuados com os gestores municipais, Ministério da Saúde e Ministério da Educação, c também a constituiçāo dos Pólos de Educação Permanente propostos pelo Ministério de Saude comos estratégias de mudança e integração da formação dos profissionais da saúde (2003-2001) sinalizam novos camininos para a formaçāo no Brasil. E, ainda, a resoluçāo no 335 do CNS (nov. /2003) sobre a Politica Nacional de Formação e Desenvolvimento para o SUS: Caminhos para a Educação Permanente em Saúde, e a I'ortaria no 198 (fev./2004) do Ministério da Sacide, que institui a Politica Nacional de Educação Permanente en Saúde, comsolidam a atual legislaçāo (mais informaçōes disponiveis no site do Alinistério da Sacide, sesesesaudegosibr).

A ratificaçāo da disposição do governo brasileiro em integrar as açòcs de cducaçĩo para n saíde aparece nitidnmente no artigo 32 do Anteprojeto de Le: da Reforma do Ensino Superior, do MEC, que diz, textualmente:

O Sistema fiederal dn Educaçño Superior serí articuladu com o Sistema línicu de Snuide - SUS, de modo a gurnutir orientaçño intersetorial no ensinu e à presingăo de serreçus de sanide, medi.

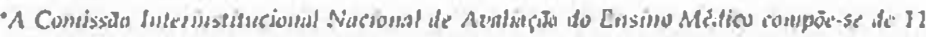

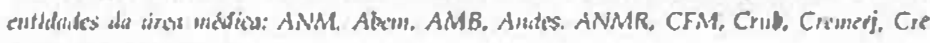
mesp, Virlem, Finam.

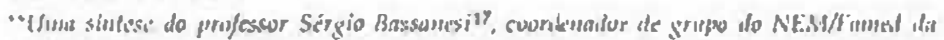

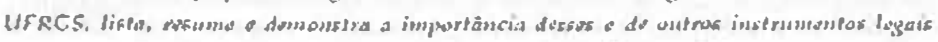

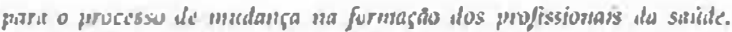


anle decisio compurtilhada guanto is normas regulatórins aplicaveis, resgunrdnndo os imbilos de competéncin do Ministério de Educaģa e do Ministirio da Snide.

Este grande movimento nacional de mudança nos currículos de faculdades da área da saúde e nos cursos de pósgraduaçảo, atualmente em andamento, sugere novas possibilidades para a educaçāo $c$ a formaçāo dos médicos.

As propostas de mudanças na Comissāo Nacional de Residência Médica, a constituiçāo da Comissāo Nacional de Residência Multiprofissional em Saúde, a instituiçāo de bolsas para a educação pelo trabalho em saúde, a serem reguladas pelo MEC c MS, em avançado estudo pelos ministćrios e próximas de assinatura pelo presidente da Répública, também constituirão poderosas ferramentas das politicas de Estado para a formação de recursos humanos $c$ a organização do SUS`.

A Faculdade de Medicina da Universidade Federal do Rio Grande do Sul, selecionada no Promed, por exemplo, discute mudanças fundamentais no cenário da formaçāocurricular, com a inserçăo precoce c permanente dos alunos na rede básica, em atividades práticas de complexidade e responsabilidade crescentes, por meio de uma disciplina-tronco, de práticas de atençăo à saúde (P^S), com açōes integradas à equipe multidisciplinar da Uß3S. Na l’^S, está previsto que se articulem todas as disciplinas básicas e clínicas ao longo dos vito primeiros semestres do curso. $\mathrm{O}$ objetivo é permitir que us alunos recém-formados tenham uma idéia muito clara a respeito das diferentes formas em que se constituem a saúde c o adoccer da populaçāo. E que também, por meio do aprendizado no próprio local da assistência, estejam aptos para a inserçăo profissional numa suciedade especifica, a nossa sociedade brasileira, com o aprendizado básico bem consulidado para corresponder às necessidades concretas de assistência à saúde dessa populaçāo."

Oprincipal cenário da formaçāo especializada cm serviço, na área da saúde, continua sendo o hospital de ensino, cujo papel se destaca na alta e média complexidades e na pesquisa e formação dos recursos humanos para a saúdc. O hospital é, portanto, central e determinante tanto na organizaçảo da as-

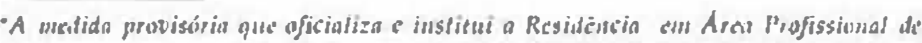
Sanife, excelluada a millica. e cria a Comisido Nacional de Residencia Mlublipuofissional

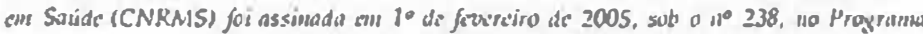

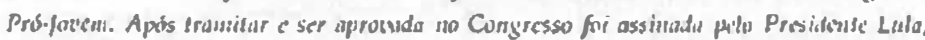

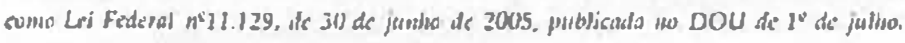

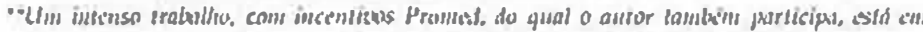
andanuento na Fasuldade de Modicina de LIFKCS. por mejo do Nrísto de Ensino Mético

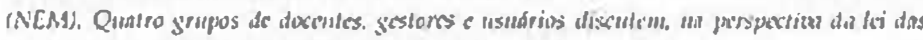

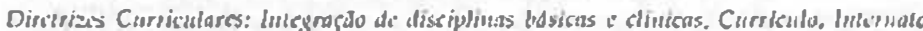

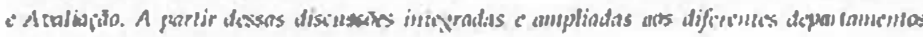

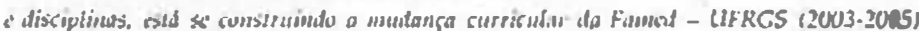

sistência do SUS, quanto na educação em saúde è na agenda de pesquisas que o Brasil necessita18,14.20.

$\Lambda$ própria organizaçāo dos serviços médicos nos hospitais de ensino, contudo, conduziu ao desenvolvimento autionomo dos serviços, independentemente de marcos regulatórios sociais ou de cuidados com a saúde do conjunto da populaçāo e a eqüiidade em relaçño ao acesso, ao risco, à vulnerabilidade. No âmbito de uma ampla discussāo que envolve a reforma do sistema hospitalar brasileiro, estas questỉes também estāo sendo enfrentadas.

Na distribuiçāo dos recursos disponiveis, lambém a prevalência das patologias foi descuidada, produzindo uma alta concentraçāo de gastus com grupos restritus de pacientes portadores de alguns tipos de doenças, enquanto outras, que atingem grande parte da populaçăo mais carente, ficam menos assistidas.

$\Lambda$ regionalizaçāo dos atendimentos $c$ a organiłaçāo em rede dos sistemas loco-regionais, desde a atenção básica nas unidades de PSF atć os atendimentos ambulatoriais especializados ou hospitalares, representam uma lógica que precisa ser incorporada nāo só pelos gestores, mas também pelos usuários, estudantes e profissionais da saúde, pois, de fato, esta é a lógica do acesso e da assistência e corresponde à possibilidade de organização racional c justa do SUS. A regulaçảo do acesso ao sistema precisa ser respeitada, mas agilizada. $O$ SUS nāo sc constituirá adequadamente se o sistema da rede básica de assisléncia, nos municípios, nāo for forte e resolutivo.

$\Lambda$ formaçāo curricular, as residências médicas c as residências multiprofissionais integradas em saúde devem se desenvolver em todos estes cenários, incorporando estudantes, docentes e profissionais em toctos os programas do SUS, participando da construção do mesmo e aprendendo a ser profissionais da salide também por meio da convivência com as pessoas, as familias e as comunidades que compõem a nossa população. Estes sño temas cen trais na discussão da formaçāo dos recursos humanos para a saúde.

As políticas públicas do Estado brasilciro ainda nảo conseguiram influenciar de maneira decisiva o ordenamento da cducaçăo em saúdc.

Dianle desse quadro, conclui-se também pela urgência cm regular 0 acesso aos programas de residência médica, reduzindo as vagas para determinadas especialidades caumentando as vagas para outras, principalmente nos hospitais da rede pública**", subre os quais pode haver mais controle. Este

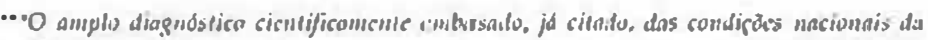

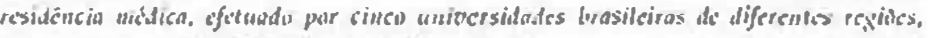

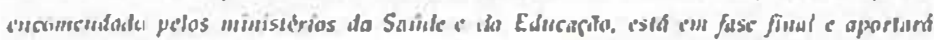

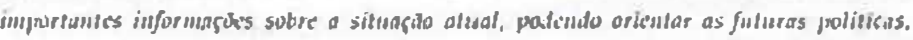


é um dever do Estado - c, constitucionalmente, dos gestores do SUS -, que deverá ser cumprido de forma pactuada, mas firme e progressiva, com os hospitais de ensino, evitando-se a ocorrência de quebra técnica na assistência prestada. $\Lambda$ substituição, nesses serviços, de residentes por médicos contratados poderá corrigir o excesso de profissionais que ingressam no mercado já saturado e, ao mesmo tempo, absorver parte dos profissionais disponiveis, desempregados ou fora da especialidade. O diagnóstico claro e a regulação permanente, avalizados pelas entidades médicas, poderão colaborar para o aperfeiçoamento do sistema de saúde, evitando ainda a frustração dos jovens médicos egressos da residência, quando não conseguem trabalho por falta de mercado.

Também são necessárias mudanças criativas na própria residência, com a incorporação de práticas que representem a humanização da formação.

É preciso enfrentar a constatação de que, entre todas as especialidades, somente cerca de $2,8 \%$ dos médicos brasileiros incluidos no SUS são generalistas, contra cerca de $50 \%$ ou mais nos sistemas de saúde da Inglaterra ou Canadá, por cxemplo. Isto decorre de uma grande escassez de centros formadores de médicos de familia e comunidade, parecendo haver, atć agora, uma incompreensão de governantes, entidades médicas $\mathrm{c}$ instituiç̧̄es de saúde quanto à importància de ampliar os locais de formação desses especialistas em familia e comunidade.

O Grupo Hospitalar Conceição, de l'orto Alegre, mantém um Serviço de Saúde Comunitária com 12 unidades de atenção primária è é referência como centro formador de recursos humanos para o SUS, com um reconhecido programa de residência de médicos de familia e comunidade, além da residência integrada em saúde, multiprofissional, que iniciou no ano de 2004. Nestas unidades básicas se desenvolve também a capacitação de equipes multiprofissionais, treinamento de equipes de P'SF para municipios vizinhos, capacitação para o diagnóstico e tratamento de pacientes HIV /aids, desenvolvimento de protocolos clinicos para a rede básica, produção de cartilhas de educação para a saúde, atendimento domiciliar $e$, ainda, estágios curriculares para diversos cursos, superiores ou técnicos, entre outras atividades de ensino em campo de assistência. OSSC/GHC apresenta resolutividade de $92 \%$ na assistência prestada a uma população adscrita de cerca de 125 mil pessoas, podendo servir de modelo de politica pública exitosa na formação de recursos humanos e na promoção de saúde $\mathrm{em}$ nosso pais ${ }^{\cdots \cdots}$.

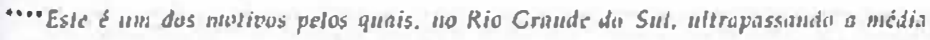

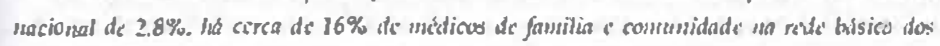

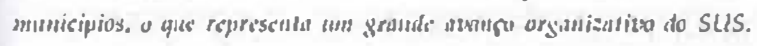

$\mathrm{Na}$ área da saude, disputas ideolígicas e políticas com múltiplos interesses estão estabelecidas. Em relação ao SUS, manifestam-se, nos extremos, os que a ele se opõem c gostariam de vê-lo fracassar e outros que o idcalizam, afirmando como dogma as suas virtudes, sem considerar os seus limites, o que muitas vezes impede de pensá-lo de forma critica e transformá-lo positivamente. Precisamos, contudo, buscar novos protagonistas, públicos ou privados, para ampliar a sua construção com outras inventividades de gerenciamento cooperativo e alianças que o potencializem $\mathrm{em}$ beneficio da melhor assistencia às pessoas, reconhecendo a diversidade $\mathrm{c}$ heterogeneidade das realidades locais e regionais dos serviços de satide, hospitais, estados e municipios.

$O$ enfoque da bioética encerra esta reflexão. Refere-se à necessidade de uma ética afirmativa a ser construida coletivamente, atenta à justiça e à eqüidade, capaz de apontar o valor bioético da utilização de critérios epidemiológicos e indicadores sociais para a justa alocação de recursos e a disponibilização de equipamentos, tecnologias e cuidados em beneficio das pessoas mais carentes e nas localidades com menores recursos. A ética da formação dos profissionais de saúde deve acolher as demandas da assistência e os objetivos sociais da pesquisa, todos integrados em torno das necessidades da população.

É de vital importância fuurdar uma referência ética coletiva no contexto das açóes e das atitudes de sujeitos anônimos ou públicos, profissionais da saúde de todas as categorias, necessariamente entre eles os médicos, usuários que participam nos conselhos de saúde, pacientes do sistema, gestores, dirctores de hospitais, docentes c muitos outros que trabalham para aprimorar o modelo da saúde. l'ara a construção do SUS, são necessárias desde práticas tecnoassistenciais eficazes atć a gestāo politico-administrativa participativa e integrada dos diferentes serviços de saúde.

Í: indispensável salientar também a centralidade, neste processo, de todas as questōes referentes à pesquisa, ao ensino e à educação. Dessa busca depende a reconstrução dos valores inerentes às profissōes da saúde e, através de exemplos dos que procuram a sua própria formação permanente, profissional e moral, a incorporação destas atitudes nos alunos $\mathrm{c}$ profissionais formados. Numa visão mais ampla, todas estas açōes configuram questōes éticas fundamentais, relacionadas ao respeito à dignidade das pessoas.

\section{REFERÊNCIAS}

1. Bernard J. Esperanças e sabedoria da Medicina. São l'aulo: Ed. Unesp: 1997.

2. Santos BS. Um discurso sobre as Ciências. São Paulo: Cortez; 2003. 
3. Declaraçāo de Alma-Ata. Conferência internacional de Alma-Ata, Cazaquistão, 12 de setembro de 1978.

4. Beauchamp T, Childress J. Principios de Ética Biomédica. São I'aulo: Loyola; 2002.

5. Apel Karl - Otto. Ln siluacion del hombre como problemn éfico. In: Razón, Ética y P'olitica. Barcelona: Anthopos; 1989.

6. Jonas H. El Principio de Responsabilidad. Barcelona: Herder; 1995.

7. Meyer P. A Irresponsabilidade Médica. São I'aulo: Ed. Unesp; 2000.

8. Triguciro MCS. O Clone de P'rometeu - a biotecnologia no Brasil: uma abordagempara a avaliação. Brasília: Unb; 2002.

9. Brasil. Ministério da Saude. P'oliticas de Formaçāo c Desenvolvimento para o SUS: caminhos da educação permanentc em saúde. Disponivel em: http:/ / www.saudc.gov.br Acesso cm: ago. 2003.

10. Melciro AMAS. O médico como paciente. Sāo P’aulo: Lemos; 2000.

11. Lampert J13. Tendências de mudanças na formação médica no Brasil. Sāo I'aulo, Rio de Janeiro: Hucitec, Abem; 2002.

12. Hottois G. O paradigma Bioćtico. Lisboa: Salamandra; 1990.

13. Rego S. A formação Ética dos Médicos. Rio de Janciro: F.d. Fiocruz; 2003.

14. Urtiaga MEO. A mediaçion da cultura docente na formaçāo médica. Pelotas, RS: UFPEL,; 2004.

15. Marins JJN, Rego S, Lampert JB, Arauijo JGC. Educaçāo Médica em transformação: instrumentos para a constru- çào de nov'as realidades. São Paulo, Rio de Janciro: Hucitec, Abem; 2004.

16. Bulcào I.C. O Ensino Médico c os novos cenários de ensino-aprendizado. Rev Bras Educ Med. 2004; 28(1):61-72.

17. Bassanesi SL. Compilação de Bases Legais. Resumo sintese de L.egislaçñes sobre Educação para a Saúde. I’orto Alegre, RS: NEM/FAMED, UFRCS; 2004.

18. Brasil. Ministério da Educaçảo. Reforma da Educaçāo Superior (anteprojeto de lei). Brasilia, DF: MEC; 2004.

19. Brasil. Ministério da Saude. Reforma do Sistema Hospitalar Brasileiro. Brasilia, DF: MS; 2004.

20. Amoretti R. O presente e o futuro dos hospitais de ensino. In: GHC, SMS/l'OA, A BRAHUli, Seminário dos Hospitais de Ensino da Regiāo Sul; 2004 5-6 ago 2004, Grupo Hospitalar Conceição, l'orto Alegre. Disponivel em: http:// www.ghc.com.br

\section{Agradecimentos:}

Agradeço a contribuiçāo de Júlio Hocsman, Airton Stein, Luiz Ziegelman, Sérgio Sirena, Júlio Baldisserotto, Juliana Amoretti e Sérgio Bassanesi pela leitura atenta c pelas críticas que ofereceram, muitas delas incorporadas neste artigo.

\section{Endereço para correspondência}

Rua Santa Teresinha, 645 - apto. 201

90040-180 - P'orto Alegre - RS

c-mails: amoretti@ghc.com.br e ranna®terra.com.br 